\title{
How Were Encounters Initiated That Resulted in the Fatal Shooting of Civilians by Police?
}

\author{
Emma Frankham, University of Wisconsin-Madison \\ frankham@wisc.edu \\ orcid.org/0000-0001-7040-5941
}

An abbreviated version of this paper has been published in Contexts:

http://journals.sagepub.com/doi/full/10.1177/1536504218776970

\begin{abstract}
This paper examines police-public encounters that resulted in the fatal shooting of civilians during 2015 and 2016. Data published by The Washington Post is merged with data collected by the author regarding how encounters were initiated. Descriptive analysis and basic statistical analysis is performed and the results indicate that how police contact was initiated varies by race/ethnicity, age, sex, mental health status, and whether (or how) the individual killed by police was armed with a weapon. The implications of the results for understanding police use of force are discussed. This paper recommends that databases on civilian fatalities include information on how contact was initiated. Without this crucial information, understandings of police use of force are incomplete.
\end{abstract}

Keywords: police, use of force, race/ethnicity, mental illness

It has been estimated that during 2015 and 2016, 1,954 individuals were fatally shot by police in the United States (The Washington Post, 2016). While the fatal shooting of civilians by police is not a new phenomenon, policing in the United States has recently been described as being in the "midst of a legitimacy crisis" following the widely publicized deaths of individuals captured on video by citizens (Nix, Campbell, Byers, 
and Alpert, 2017, p.310). While researchers have considered the possibility of implicit bias by police officers and racial differences in whether individuals killed by police were armed (Nix et al., 2017), research has not considered why the police were in contact with these individuals in the first place.

Some of the most high profile police killings were initiated by the police themselves. For example, Keith Lamont Scott was killed when police officers encountered him with a gun as they were in the process of serving a warrant on another individual (Lowery and Thompson, 2016). The widely-publicized death of Samuel DuBose in Cincinnati, Ohio, occurred following a traffic stop (Berman, 2017). But are these cases representative of how police-public interactions that result in civilian fatality were initiated? Furthermore, are there demographic differences in how these encounters were initiated? For example, by sex, race/ethnicity, or age? Are there differences by mental health status or whether an individual had a weapon? This paper answers these questions by descriptively investigating how police interactions that resulted in civilian fatalities during 2015 and 2016 were initiated.

\section{What we (Don't) Know about Deadly Force}

Researchers have been examining police use of deadly force for over 50 years from a range of perspectives, none of which have considered how police contact was initiated. For example, regarding police-public trust surrounding situations where an individual is fatally shot by police, Fyfe (1981) highlights the difficulty in ascertaining what really happened at the site of a police shooting. The public may also have skepticism regarding the validity of official accounts surrounding those events (Fyfe, 1981).

Regarding the demographic characteristics of individuals fatally shot by police, 
several scholars have argued that individuals fatally shot by police are disproportionately African-American (Goldkamp, 1976; Robin, 1963). Furthermore, recent research indicates that African-American individuals fatally shot by police were over twice as likely than White individuals to have been unarmed (Nix et al. 2017). Historically, it has been argued that individuals fatally shot by police are overwhelmingly male, most resist arrest, and two thirds have a criminal record (Robin, 1963).

Research on the relationship between fatal shootings of civilians by police and the incidence of criminal homicide has conflicting results. Langworthy (1986) examined fatal police shootings and incidences of criminal homicides in New York City that occurred between 1971 and 1975 and found no temporal relationship between the two. However, MacDonald, Kaminski, Alpert, and Tannenbaum (2001) used the Federal Bureau of Investigation's Supplementary Homicide Reports over a 21-year period to argue that there is a temporal connection. Furthermore, using Uniform Crime Reports, Census data, and Law Enforcement Management and Administrative Statistics, Smith (2004) argued that measures of both racial threat and community violence are related to fatal shootings of civilians by police.

From an organizational perspective, Reiss (1980) argued that attempts to control police use of lethal force should consider the role of police departments in controlling opportunities to use lethal force. Fatal police shootings have also been examined from a social psychological perspective that has examined the potential biases present in decisions to shoot (Kahn and McMahon, 2015). However, again this research does not consider reason for police contact, but instead starts analysis at the point of police contact. 
The legal context, in particular the impact of the U.S. Supreme Court decision in Tennessee v. Garner (1985), has also been examined. Justice White, writing for the majority, opined: "We conclude that such force [lethal] may not be used unless it is necessary to prevent the escape and the officer has probable cause to believe that the suspect poses a significant threat of death or serious physical injury to the officer or others." Prior to Tennessee v. Garner (1985), most jurisdictions believed that the use of lethal force by police was justified for all felonies (Tannenbaum, 1994). Sparger and Giacopassi (1992) used Memphis Police Department data to argue that as a result of changes in police department policies following the Supreme Court decision, "both the overall shooting rate and the apparently discriminatory application of lethal force in Memphis were reduced greatly" (p. 224). Using Uniform Crime Reports data and Supplementary Homicide Reports, Tannenbaum (1994) argued that there was a reduction of fatal police shootings, to the magnitude of approximately 16 percent nationally.

What we do not know about fatal police encounters is why police were there in the first place. Some researchers have examined how police encounters were initiated that did not result in death. For example, Engel, Shepard, Sobol, and Worden (2000) record an "entry" variable in their analysis of both arrest decisions and less-than-lethal force. This binary variable captured whether the encounter was initiated by citizens or dispatch, or whether it was officer-initiated. They found that the entry variable is not statistically significant in relation to either arrest or use of force. Fridell and Lim (2016), using a binary variable that indicated whether contact was initiated by a service call, found that 911 call initiated encounters are associated with a higher likelihood that "soft empty hand control techniques" (p. 42) will be used rather than 
intermediate force. Similarly, Terrill and Mastrofski (2002) find that "proactive stops were significantly more likely to involve higher levels of force" (p. 239). They hypothesize that this is because "officers are placing the responsibility on themselves to intervene in the lives of citizens" (p. 239). Garner, Maxwell, and Heraux (2002) argued that "how an officer approaches a scene appears to have a consistent impact on the amount of force used in arrests" (p. 736). Officer-initiated contacts that result in arrest are associated with a greater prevalence of force, however they are not associated with greater severity (Garner et al., 2002).

However, research to date has not examined more nuanced information regarding how police incidents are initiated. For example, if it was a 911 call that initiated the encounter, who called? Are there demographic or behavioral differences regarding who called 911? Furthermore, there has been no examination at all regarding how fatal police encounters are initiated. This paper posits the view that police-public contact begins at the point of police awareness of the individual. This may be institutional-level awareness, such as a 911 call operator receiving a call about an individual, or a police department making the decision to execute a warrant, or officer-level awareness, such as a police officer deciding to approach an individual.

\section{Data}

There are several federal government databases that record police use of non-lethal, and lethal, use of force. These databases include the Federal Bureau of Investigation Uniform Crime Reports (1929-present); the Deaths in Custody Reporting Program (2000-present); the Arrest-related Deaths Program (2003-present); and the most recent endeavor, the Police Data Initiative (2015-present). However, there are concerns 
regarding the accuracy of these sources and in 2015 alone The Washington Post recorded approximately twice as many fatal civilian shootings by police than had been reported by the Federal Bureau of Investigation (Kindy et al., 2016). Furthermore, Uniform Crime Reports do not contain information on the mental health status of civilians killed by police (Fuller et al., 2015). The Deaths in Custody Reporting Program, while it includes mental health information, is not funded or enforced (Fuller et al., 2015). The Arrest-related Deaths Program also includes mental health information, however, again, it is not funded. Furthermore, the data is based on incomplete Uniform Crime Reports data (Fuller et al., 2015). In 2014, the program was temporarily suspended because of inconsistent and incomplete data that did not meet Bureau of Justice Statistics data quality standards (Fuller et al., 2015).

Due to these data limitations, this paper uses publicly available data published by The Washington Post in conjunction with data collected by the author. The data used that was published by The Washington Post recorded incidences between January 1, 2015 and December 31, 2016 in the United States in which a police officer, in the line of duty, fatally shot a civilian (Fuller et al., 2015). Data was gathered using a combination of investigative journalism, examining police records obtained by open records requests, and examining other Internet sources (Fuller et al., 2015). The data includes demographic information about civilians killed such as age, race/ethnicity, and gender. The variable age was coded by the author into four categories of age groups that mirror US Census reporting: under 18; 18-44; 45-64; 65 and over.

The Washington Post data also includes includes information on whether, or how, the civilian was armed. The armed variable was coded from the original data into the following three categories: unarmed; armed with a non-projectile weapon (such as a 
knife); and armed with a projectile weapon (such as a conducted electrical weapon or a gun). Toy weapons were included in the latter category because of their visual similarity to guns. The data reports mental health information by analyzing and reporting the presence of indicators in media reports that the individual killed by police had mental health problems (Fuller et al. 2015).

Between 2015 and 2016, The Washington Post recorded 1,954 individuals killed by police. However, The Washington Post data contained some missing data for variables that were required for analysis. These cases were removed from the data. For 91 cases the race/ethnicity was missing. Individuals who were reported as being Native American $(n=25)$, Asian $(n=29)$, or of "other" race/ethnicity $(n=26)$ were removed from the data because of the small sample sizes. In 37 cases the age was missing. Whether the individual was armed was missing in five cases and "undetermined" in 91 cases. In both of these situations the cases were removed from the data.

Information regarding every encounter recorded by The Washington Post was cross-referenced for accuracy against online news reports and following this process some amendments to the data were made. For example, Jeremy Lett and Desmond Luster were included in the original data but should not have been because they were killed by off-duty police officers. These cases were removed from analysis. Tony Robinson was initially recorded as not having mental illness, but news reports indicated otherwise so this case was amended.

The author then searched for online news reports about individuals killed by police to gather information on how the police contact was initiated. This information gathered by the author was coded into the following six categories of contact initiation 
and added to The Washington Post data:

1. Contact initiated by a patrol officer. For example, a traffic stop.

2. Contact initiated by a local police department issuing a warrant or investigating a suspect.

3. Contact initiated by a SWAT team or US Marshals issuing a warrant or investigating a suspect.

4. Contact initiated by a family member or friend calling 911 .

5. Contact initiated by someone other than a family member or friend calling 911 .

6. Contact initiated by the individual who was subsequently killed calling 911 .

A categorical variable that recorded how police contact was initiated was created For 310 individuals who were killed by police, information could not be found in news reports regarding how the police contact was initiated. These individuals were removed from the data. The author does not have concerns about this missing data affecting the representativeness of analysis. Comparing the attributes of the individuals for whom data is missing to the complete data, the missing data appears to be randomly distributed by the following demographic variables used in analysis: race/ethnicity, age, and gender. Following the above exclusions, 1,340 unique instances of individuals fatally shot by police during 2015 and 2016 remained in the data.

\section{Analysis and Results}

For the analysis, the chi-square statistic was calculated for how contact was initiated and the following variables: race/ethnicity (Table 1); age (Table 2); mental health status (Table 3); and whether the individual was armed and with what type of weapon (Table 4). Fisher's exact test statistic was calculated for the association between how 
contact was initiated and sex (Table 5).

Table 1. How Police Contact was Initiated by Race/ethnicity

\begin{tabular}{lllll}
\hline & White & Black & Hispanic & Total \\
\hline Patrol Officer & $107(41 \%)$ & $96(37 \%)$ & $58(22 \%)$ & $261(100 \%)$ \\
& $(15 \%)$ & $(25 \%)$ & $(25 \%)$ & $(19 \%)$ \\
Local Police Department Warrant/Investigation & $111(54 \%)$ & $68(33 \%)$ & $27(13 \%)$ & $206(100 \%)$ \\
& $(15 \%)$ & $(18 \%)$ & $(12 \%)$ & $(15 \%)$ \\
SWAT or US Marshals Warrant/Investigation & $40(53 \%)$ & $27(36 \%)$ & $9(12 \%)$ & $76(6 \%)$ \\
& $(6 \%)$ & $(7 \%)$ & $(4 \%)$ & $(6 \%)$ \\
Family/Friend 911 Call & $195(74 \%)$ & $36(14 \%)$ & $32(12 \%)$ & $263(100 \%)$ \\
Someone Other than Family/Friend 911 Call & $(27 \%)$ & $(9 \%)$ & $(14 \%)$ & $(20 \%)$ \\
Self 911 Call & $243(49 \%)$ & $159(32 \%)$ & $99(20 \%)$ & $501(100 \%)$ \\
& $(34 \%)$ & $(41 \%)$ & $(43 \%)$ & $(38 \%)$ \\
\hline Total & $28(85 \%)$ & $0(0 \%)$ & $5(15 \%)$ & $33(100 \%)$ \\
& $(4 \%)$ & $(0 \%)$ & $(2 \%)$ & $(2 \%)$ \\
\hline
\end{tabular}

Note: Pearson chi-square $(10)=89.6390, \mathrm{p}<.001$

The results from Table 1 indicate that the most common reason for police contact among those killed by police was someone other than a family member or friend calling 911, accounting for $38 \%$ of the encounters. Approximately $17 \%$ of those killed by police were Hispanic, 29\% were African-American, and $54 \%$ were White. The second most common reason for contact was a family member or friend calling police, and this was much more common for Whites than African-Americans or Hispanics killed by police. Patrol-officer initiated encounters were the third most common reason for contact, and these were much more likely for Hispanics or African-Americans killed by police than Whites. Local police department warrant or investigation initiated contact accounted for $15 \%$ of encounters. The least common types of contact initiation are contact initiated by SWAT or US Marshals (6\%), and the individual killed calling 911 themselves $(2 \%)$. 
Table 2. How Police Contact was Initiated by Age

\begin{tabular}{llllll}
\hline & Under 18 & $18-44$ & $45-64$ & $\begin{array}{l}65 \text { and } \\
\text { Over }\end{array}$ \\
\hline Patrol Officer & & & & Total \\
& $5(2 \%)$ & $214(82 \%)$ & $39(15 \%)$ & $3(1 \%)$ & $261(100 \%)$ \\
& $(20 \%)$ & $(22 \%)$ & $(13 \%)$ & $(10 \%)$ & $(18 \%)$ \\
Local Police Department Warrant/Investigation & $3(1 \%)$ & $156(76 \%)$ & $45(22 \%)$ & $2(1 \%)$ & $206(100 \%)$ \\
& $(12 \%)$ & $(16 \%)$ & $(14 \%)$ & $(7 \%)$ & $(15 \%)$ \\
SWAT or US Marshals Warrant/Investigation & $0(0 \%)$ & $66(87 \%)$ & $10(13 \%)$ & $0(0 \%)$ & $76(100 \%)$ \\
& $(0 \%)$ & $(7 \%)$ & $(3 \%)$ & $(0 \%)$ & $(6 \%)$ \\
Family/Friend 911 Call & $3(1 \%)$ & $154(59 \%)$ & $95(36 \%)$ & $11(4 \%)$ & $263(100 \%)$ \\
Someone Other than Family/Friend 911 Call & $(12 \%)$ & $(16 \%)$ & $(30 \%)$ & $(38 \%)$ & $(20 \%)$ \\
Self 911 Call & $13(3 \%)$ & $368(73 \%)$ & $108(22 \%)$ & $12(2 \%)$ & $501(100 \%)$ \\
& $(52 \%)$ & $(38 \%)$ & $(35 \%)$ & $(41 \%)$ & $(38 \%)$ \\
\hline Total & $1(3 \%)$ & $16(48 \%)$ & $15(45 \%)$ & $1(3 \%)$ & $33(100 \%)$ \\
& $(4 \%)$ & $(2 \%)$ & $(5 \%)$ & $(3 \%)$ & $(2 \%)$ \\
\hline
\end{tabular}

Note: Pearson chi-square $(15)=66.3915, \mathrm{p}<.001$

Table 3. How Police Contact was Initiated by Mental Health Status

\begin{tabular}{llll}
\hline & Person without MI & Person with MI & Total \\
\hline Patrol Officer & $231(89 \%)$ & $30(12 \%)$ & $261(100 \%)$ \\
& $(23 \%)$ & $(9 \%)$ & $(19 \%)$ \\
Local Police Department Warrant/Investigation & $176(85 \%)$ & $30(15 \%)$ & $206(100 \%)$ \\
SWAT or US Marshals Warrant/Investigation & $(18 \%)$ & $(9 \%)$ & $(15 \%)$ \\
& $71(93 \%)$ & $5(7 \%)$ & $76(100 \%)$ \\
Family/Friend 911 Call & $(7 \%)$ & $(1 \%)$ & $(6 \%)$ \\
Someone Other than Family/Friend 911 Call & $125(48 \%)$ & $138(52 \%)$ & $263(100 \%)$ \\
Self 911 Call & $(12 \%)$ & $(41 \%)$ & $(20 \%)$ \\
& $(391(78 \%)$ & $110(22 \%)$ & $501(100 \%)$ \\
Total & $9(27 \%)$ & $(33 \%)$ & $(38 \%)$ \\
& $(1 \%)$ & $24(72 \%)$ & $33(100 \%)$ \\
\end{tabular}

Note: Pearson chi-square $(5)=198.7317, \mathrm{p}<.001$ 
Table 2 shows how police contact was initiated by age. The majority of those killed by police $(73 \%)$ were age $18-44$. The most common cause of contact across all age categories was a family member or friend calling 911 . Table 3 displays differences in how police contact was initiated by mental health status. Approximately $25 \%$ of fatal police encounters were with persons with mental illness. These encounters were most likely initiated by a family member or friend calling 911 . Police encounters with persons without mental illness were most likely initiated by someone other than a family member or friend calling 911.

Table 4. How Police Contact was Initiated by Whether Armed

\begin{tabular}{lllll}
\hline & Unarmed & $\begin{array}{l}\text { Non-Projectile } \\
\text { Weapon }\end{array}$ & $\begin{array}{l}\text { Projectile } \\
\text { Weapon }\end{array}$ & Total \\
\hline Patrol Officer & $43(16 \%)$ & $60(23 \%)$ & $158(61 \%)$ & $261(100 \%)$ \\
& $(36 \%)$ & $(17 \%)$ & $(18 \%)$ & $(19 \%)$ \\
Local Police Department Warrant/Investigation & $19(9 \%)$ & $42(20 \%)$ & $145(70 \%)$ & $206(100 \%)$ \\
SWAT or US Marshals Warrant/Investigation & $(16 \%)$ & $(12 \%)$ & $(17 \%)$ & $(15 \%)$ \\
& $(6 \%)$ & $(9 \%)$ & $61(80 \%)$ & $76(100 \%)$ \\
Family/Friend 911 Call & $14(5 \%)$ & $94(36 \%)$ & $15 \%(59 \%)$ & $263(100 \%)$ \\
Someone Other than Family/Friend 911 Call & $(12 \%)$ & $(26 \%)$ & $(18 \%)$ & $(20 \%)$ \\
Self 911 Call & $34(7 \%)$ & $139(28 \%)$ & $328(65 \%)$ & $501(100 \%)$ \\
& $(29 \%)$ & $(39 \%)$ & $(38 \%)$ & $(38 \%)$ \\
Total & $1(3 \%)$ & $14(42 \%)$ & $18(55 \%)$ & $33(100 \%)$ \\
\hline
\end{tabular}

Note: Pearson chi-square $(10)=54.4159, \mathrm{p}<.001$ 
Of those killed by police, $65 \%$ had a projectile weapon, $27 \%$ had a non-projectile weapon, and $9 \%$ were unarmed (table 4 ). Among those who had a projectile weapon or non-projectile weapon the most common cause of contact was someone other than a family member or friend calling 911 . In contrast, the most common cause of contact for those who were unarmed was patrol officer-initiated contact.

Table 5. How Police Contact was Initiated by Sex

\begin{tabular}{llll}
\hline & Female & Male & Total \\
\hline Patrol Officer & $4(2 \%)$ & $257(98 \%)$ & $261(100 \%)$ \\
Local Police Department Warrant/Investigation & $(6 \%)$ & $(20 \%)$ & $(19 \%)$ \\
SWAT or US Marshals Warrant/Investigation & $2(3 \%)$ & $192(93 \%)$ & $206(100 \%)$ \\
& $(3 \%)$ & $(15 \%)$ & $(15 \%)$ \\
Family/Friend 911 Call & $17(6 \%)$ & $24 \%(97 \%)$ & $76(100 \%)$ \\
& $(27 \%)$ & $(19 \%)$ & $(6 \%)$ \\
Someone Other than Family/Friend 911 Call & $22(4 \%)$ & $479(96 \%)$ & $263(100 \%)$ \\
& $(35 \%)$ & $(38 \%)$ & $(37 \%)$ \\
Self 911 Call & $4(12 \%)$ & $29(88 \%)$ & $33(100 \%)$ \\
& $(6 \%)$ & $(2 \%)$ & $(2 \%)$ \\
\hline Total & $63(5 \%)$ & $1277(95 \%)$ & $1340(100 \%)$ \\
& $(100 \%)$ & $(100 \%)$ & $(100 \%)$ \\
\hline
\end{tabular}

Note: Fisher's exact $\mathrm{p}<.01$

The vast majority (95\%) of those killed by police were male (table 5). For both men and women the most common cause of contact was someone other than a family member or friend calling 911. For women, the least common type of contact was contact initiated by SWAT or US Marshals, whereas for men the least common type of contact was calling 911 themselves. 


\section{Discussion}

It should be noted that this paper does not examine how police contacts were initiated that resulted in deadly force in the United States, but rather it examines how police contacts were initiated that resulted in the death of civilians following police use of deadly force. As Fyfe argued, deadly force is "physical force capable of or likely to kill; it does not always kill" (1978:32). Klinger (2012) echoes this concern that individuals killed by police is not a metric for police use of deadly force. As data collection improves, it may be possible to examine how interactions where the use of deadly force did not result in a civilian being killed were initiated.

The results indicate that of those killed by police during 2015 and 2016 the most common reason for contact was someone other than a family member or friend calling 911. However, there were differences by race/ethnicity, age, sex, mental health status, and whether (or how) the individual killed by police was armed with a weapon. For example, African-Americans killed by police were approximately a third as likely as Whites to have the encounter initiated by a family member or friend. Individuals age 45-64 and 65 and over are less likely than younger individuals killed by police to have the encounter initiated by a patrol officer. Individuals age 45-64 and 65 and over are more than twice as likely than younger individuals to have the encounter initiated by a family member or friend. Individuals with mental illness were unlikely to have contact due to a patrol officer, local police department warrant or investigation, or a SWAT or US Marshals warrant or investigation. Men were over three times as likely as women to have the encounter initiated than a patrol officer.

Methodologically, it is difficult to know for certain why there are differences in how contact was initiated, and the differences are likely a complex combination of factors. 
For example, there may have been racial/ethnic differences in willingness of family members/friends to initiate police contact. In a qualitative examination of youth attitudes toward police, Carr, Napolitano, and Keating (2007) argued that direct negative experiences with police may lead to African-American individuals not wanting to call the police in an emergency. Research has also indicated that negative vicarious experience, specifically news coverage of use of force against African-Americans, decreases violent crime reporting at the neighborhood-level in predominantly African-American neighborhoods (Desmond, Papachristos, and Kirk, 2016).

Patrol officers may be more likely to perceive threat in Hispanic and African-American individuals and decide to initiate contact such as traffic stops (Ritter, 2017), or Hispanics and African-Americans may commit more offenses in the presence of police officers, or both. Older individuals may have more favorable views of police and be more willing to engage with police. Older individuals are less likely than younger individuals to express negative attitudes toward police (Bridenball and Jesilow, 2008; Brown and Coulter, 1983; Peek, Lowe, and Alston, 1981; Worrall, 1999).

The results of this paper have implications for considering race/ethnicity and use of force. Typically in research on police use of force, race/ethnicity is treated independently of the specific cause of police interaction without a consideration of who is calling 911 and their relationship to the individual who becomes the object of police contact (Engel, Sobol, and Worden, 2000; Fridell and Lim, 2016; Garner, Maxwell, and Heraux, 2002; Gau, Mosher, and Pratt, 2010; Kahn et al., 2017; Terrill, Leinfelt, and Kwak, 2008; Terrill and Mastrofski, 2002). Because how police contact was initiated appears to be strongly associated with race/ethnicity it is important to include measures of how police contacts were initiated to disentangle the effects of 
race/ethnicity in police use of force incidents. In particular, more information may be available to police when contact is initiated by a family member or friend, which may elicit a different police response. In a study examining the effects of information on use of force, results indicated that African-Americans and Hispanics are more likely than Whites to receive use of force during the beginning stages of an interaction when information about the individual is low (Kahn et al., 2017). Other research has indicated that the effects of stereotypes are stronger in circumstances in which there is less information about the particular individual (Hilton and Fein, 1989; Hilton and von Hippel, 1996; Krueger and Rothbart, 1988).

Regarding policy implications of the results, policy makers should advocate for the inclusion of measures that indicate how police contact was initiated in any creation of national or state databases on use of force incidents. Researchers have advocated for a national database that includes information on both offender and officer characteristics, including demographic information such as race/ethnicity, age, and gender, as well as police officer professional information such as rank, education, and complaint history (Nix et al. 2017). Furthermore, Klinger et al. (2016) argued that the following minimum elements are required of a national database:

(a) the number of incidents in which police officers discharge firearms at citizens; (b) the demographic characteristics of the officers and citizens involved in each incident; (c) the agency/agencies employing the involved officers and location of each incident; (d) the particular weapon(s) used by police officers and citizens; and (e) the injuries, if any, suffered by officers and citizens (p. 215).

Alpert (2015) additionally recommended the inclusion of factors such as agency size, agency location, and the types and frequency of police officer training. However, if 
information regarding how the encounter was initiated is not included, understandings of police use of force will be incomplete. 


\section{References}

Alpert, Geoffrey P. 2015. "Toward a National Database of Officer-Involved Shootings: A Long and Winding Road." Criminology \& Public Policy 15:1-6.

Berman, Mark. 2017. "Prosecutors Won't Seek Third Trial for Former Ohio Police Officer who Shot Samuel DuBose." The Washington Post. Retrieved from: https://www.washingtonpost.com/news/post-nation/wp/2017/07/18/prosecutorswont-seek-third-trial-for-former-ohio-police-officer-who-shot-samueldubose/?utm_term $=.4028056 f 21$ ea

Bridenball, Blaine, and Paul Jesilow. 2008. "What Matters: The Formation of Attitudes Toward the Police." Police Quarterly 11:151-181.

Brown, Karin, and Philip B. Coulter. 1983. "Subjective and Ojective Measures of Police Service Delivery." Public Administration Review 43:50-58.

Carr, Patrick J., Laura Napolitano, and Jessica Keating. 2007. "We Never Call the Cops and Here is Why: A Qualitative Examination of Legal Cynicism in Three Philadelphia Neighborhoods." Criminology 45:445-80.

Desmond, Matthew, Andrew V. Papachristos, and David S. Kirk. 2016. "Police Violence and Citizen Crime Reporting in the Black Community."' American Sociological Review 81:857-876.

Engel, Robin Shepard, James J. Sobol, and Robert E. Worden. 2000. "Further Exploration of the Demeanor Hypothesis: The Interaction Effects of Suspects' Characteristics and Demeanor on Police Behavior." Justice Quarterly 172:235-258. Fridell, Lorie, and Hyeyoung Lim. 2016. "Assessing the Racial Aspects of Police Force Using the Implicit- and Counter-Bias Perspectives." Journal of Criminal Justice $44: 36-48$. 
Fuller, Doris A., H. Richard Lamb, Michael Biasotti, and John Snook. 2015.

Overlooked in the Undercounted: The Role of Mental Illness in Fatal Law

Enforcement Encounters. Retrieved from:

http://www.treatmentadvocacycenter.org/storage/documents/overlooked-in-theundercounted.pdf

Fyfe, James J. 1978. Shots Fired: An Examination of New York City Police Firearms

Discharges. Ann Arbor, MI: University Microfilms International.

Fyfe, James J. 1981. "Observations on Police Deadly Force." Crime 83 Delinquency $27: 376-389$.

Garner, Joel H., Christopher D. Maxwell, and Cedrick G. Heraux. 2002.

"Characteristics Associated with the Prevalence and Severity of Force Used by the Police." Justice Quarterly 194:705-746.

Gau, Jacinta M., Clayton Mosher, and Travis C. Pratt. 2010. "An Inquiry into the Impact of Suspect Race on Police Use of Tasers." Police Quarterly 13:27-48.

Hilton, James L., and Steven Fein. 1989. "The Role of Typical Diagnosticity in Stereotype-Based Judgments." Journal of Personality and Social Psychology $57: 501-11$.

Hilton, James L., and William von Hippel. 1996. "Stereotypes." Annual Review of Psychology 47:237-271.

Kahn, Kimberly B., Joel S. Steele, Jean M. McMahon, and Greg Stewart. 2017. "How Suspect Race Affects Police Use of Force in an Interaction over Time." Law and Human Behavior 41:117-126.

Kindy, Kimberly, Marc Fisher, Julie Tate, and Jennifer Jenkins. 2015. "A year of Reckoning: Police Shoot Nearly 1,000. The Washington Post. Retrieved from: 
http://www.washingtonpost.com/sf/investigative/2015/12/26/a-year-of-reckoning-

police-fatally-shoot-nearly-1000

Klinger, David. 2012. "On the Problems and Promise of Research on Lethal Police

Violence: A Research Note." Homicide Studies 16:78-96.

Klinger, David, Richard Rosenfeld, Daniel Isom, and Michael Deckard. 2016. "Race, Crime, and the Micro-Ecology of Deadly Force." Criminology ES Public Policy $15: 193-222$.

Krueger, Joachim, and Myron Rothbart. 1988. "Use of Categorical and Individuating Information in Making Inferences about Personality." Journal of Personality and Social Psychology 55:187-95.

Lowery, Wesley and Cheryl W. Thompson. 2016. "Autopsy Shows Keith Lamont Scott had Four Gunshot Wounds - Including One in the Back." The Washington Post. Retrieved from: https://www.washingtonpost.com/news/postnation/wp/2016/10/12/autopsy-shows-keith-lamont-scott-was-shot-four-times-bycharlotte-officer-once-in-the-back/?utm_term $=.2 \mathrm{a} 16 \mathrm{ad} 69952 \mathrm{c}$

Nix, Justin, Bradley A. Campbell, Edward H. Byers, and Geoffrey P. Alpert. 2017. "A Bird's Eye View of Civilians Killed by Police in 2015: Further Evidence of Implicit Bias." Criminology 8 Public Policy 16:309-340.

Peek, Charles W., George D. Lowe, and Jon P. Alston. 1981. "Race and Attitudes Toward Local Police: Another Look." Journal of Black Studies 11:361-374.

Ritter, Joseph A. 2017. "How do Police use Race in Traffic Stops and Searches? Tests Based on Observability of Race." Journal of Economic Behavior and Organization $135: 82-98$.

Smith, Brad W. 2004. "Structural and O rganizational Predictors of Homicide by 
Police." Policing: An International Journal of Police Strategies $\&$ Management $27(4): 539-557$.

Terrill, William, Fredrik H. Leinfelt, and Dae-Hoon Kwak. 2008. "Examining Police Use of Force: A Smaller Agency Perspective." Policing: An International Journal of Police Strategies 86 Management 31:57-76.

Terrill, William, and Stephen D. Mastrofski. 2002. "Situational and Officer-Based Determinants of Police Coercion." Justice Quarterly 19:215-248.

The Washington Post. 2016. Washington Post/ Data-police-shootings. Retrieved from: http://www.github.com/washingtonpost/data-police-shootings

Worrall, John. 1999. "Public Perceptions of Police Efficacy and Image: The 'Fuzziness' of Support for the Police." American Journal of Criminal Justice $24: 47-66$. 